\title{
Impressão em serigrafia: uma opção pela estética
}

\author{
Screen printing: an option for aesthetics
}

\author{
AMINGER, Andrea Franco; Especialista; ESPM Rio \\ andrea.aminger@gmail.com \\ MIGLIARI, Mirella De Menezes; Doutora; ESPM Rio \\ migliari@espm.br
}

\begin{abstract}
Resumo
O presente artigo discute as qualidades do processo de impressão por serigrafia, sob a ótica do designer gráfico, estabelecendo um viés comparativo com o processo de impressão digital que domina o setor gráfico na atualidade. Sendo este setor muito suscetível às mudanças tecnológicas, questiona-se quando as escolhas deverão ser pautadas por fatores como prazo de entrega e custo, e quando se deverá optar pela qualidade específica de uma técnica devido a fatores de cunho sensorial. É lançado um olhar de viés estético à contribuição da técnica de impressão serigráfica ao design gráfico, a partir de conceitos tais como estetização do mundo - Serroy e Lipovetsky (2015), estandardização - Adorno (2002), e banalização da estética - Vargas Llosa (2013). Diante de fatos históricos levantados, fica evidente que esse processo de impressão, tão antigo, está relacionado também ao resgate de uma tradição, e possui portanto um valor intrínseco de acordo com Reis (2007).
\end{abstract}

Palavras Chave: estética; design gráfico e serigrafia; tradição.

\begin{abstract}
This article discusses the qualities of the screen printing process, from the point of view of the graphic designer, establishing a comparative bias with the digital printing process that dominates the graphic industry at the present time. Since this sector is very susceptible to technological changes, it is questioned when the choices should be guided by factors such as delivery time and cost, and when to choose the specific quality of a technique due to sensorial factors. A look of aesthetic bias is given to the contribution of the technique of serigraphic printing to graphic design, based on concepts such as the aestheticization of the world - Serroy and Lipovetsky (2015), standardization - Adorno (2002), and banalization of aesthetics - Vargas Llosa (2013). In view of historical facts raised, it is evident that this process of printing, so old, is also related to the rescue of a tradition, and therefore has an intrinsic value according to Reis (2007).
\end{abstract}

Keywords: aesthetics; graphic design and screen printing; tradition. 


\section{Introdução}

Este artigo versa sobre como se dá a opção pela impressão serigráfica - em detrimento do processo digital - baseada nas qualidades estéticas inerentes à serigrafia pelo profissional da área de design gráfico. $O$ estudo se debruça sobre a elaboração de um cartão de visita, apresentando o impacto que a opção por um determinado processo tem para um trabalho de impressão a partir da comparação entre produtos oriundos de processos distintos. Para isso, analisou-se de forma aprofundada o resultado alcançado com a impressão em serigrafia, tão característico e intrínseco a este processo gráfico.

A experiência estética que a impressão em serigrafia proporciona não se compara em nada com a experiência virtual, tão aclamada atualmente. Com a impressão em serigrafia, chega-se a uma experiência estética tanto visual quanto tátil. A título de reflexão, tomaram-se os conceitos de estética apresentados em A Estetização do Mundo, obra na qual Lipovestsky e Serroy (2015) apontam "as quatro eras da estetização do mundo". A primeira era é a ritual, a segunda é a era aristocrática, a terceira é a era moderna, e a quarta, a transestética. Nesta abordagem a definição de estética que mais se aproxima desse artigo é a terceira proposta, que se relaciona com "a moderna estetização do mundo".

Tomando-se a escalada da estetização em massa, e seu universo industrial e comercial como principal artífice da estetização do mundo moderno e da sua expansão democrática, entende-se que a impressão em serigrafia teve seu início atrelado a este contexto de produção. No entanto, em tempos correntes nos quais prospera a impressão digital, a serigrafia vem sendo cada vez menos utilizada para finalidades da indústria gráfica.

Outra obra que deu sustentação às reflexões apresentadas neste estudo foi A Civilização do Espetáculo, de Vargas Llosa (2013), pois nela é apresentada a ideia da banalização das artes, e da valorização da quantidade em detrimento da qualidade. Por exemplo, a fim de ilustrar esta ideia, muitas das vezes um designer gráfico se depara com um projeto cuja simplicidade poderia ser valorizada e alavancada através de recursos de produção gráfica - a escolha pela impressão em serigrafia seria um desses recursos. Porém, devido à incompreensão de seu cliente, este designer precisa fazer a opção pela impressão digital em detrimento da impressão serigráfica. Entende-se que seu cliente esteja à procura da impressão em maior quantidade, por um menor custo, com uma entrega mais rápida. Nessa situação corriqueira, o cliente final não está atento ou sensível à qualidade superior do produto final que a serigrafia proporciona, e nem mesmo ao resultado estético diferenciado. Neste processo, tem-se uma perda estética e do valor agregado a ela.

\section{Qualidade versus quantidade e prazo}

O profissional da área de design gráfico, quando está envolvido em um determinado projeto, irá percorrer várias etapas. Para melhor compreensão daquilo que se quer discutir aqui, toma-se como exemplo a criação e produção de uma peça gráfica bastante popular, comum e corriqueira: o cartão de visita (business card). 0 trabalho se inicia com o briefing, que é a síntese do entendimento das necessidades/problemas de seu cliente. Em seguida, virá o desenvolvimento das ideias para as soluções - geração de alternativas, com a criação de layouts de apresentação, os quais, ao final deste processo, são apresentados ao cliente para aprovação.

Alcançada a aprovação de um projeto de design gráfico, esse profissional deverá também 
apresentar os orçamentos de produção a partir de alguns possíveis processos disponíveis, para se chegar aquele mais adequado ao conceito. No caso do cartão de visita, pode-se indicar a serigrafia ou a impressão digital no caso de pequenas e médias tiragens. Portanto, entende-se que um processo concorra com o outro neste setor. Uma vez definida a gráfica, esse profissional deverá finalizar o arquivo digital para impressão. Em seguida, a gráfica se encarregará da impressão, acabamentos e entrega.

Conforme é possível identificar acima, o designer gráfico transita por um longo processo a fim de adequar sua ideia (conceito) à produção ideal, aquela que melhor a tangibilize e valorize, e é através da equação destes fatores que esse profissional será bem reconhecido no seu meio profissional.

Segundo Gordon (2014), as etapas pouco afetadas pela tecnologia, nas quais os profissionais se distinguem, são a geração de ideias e o desenvolvimento de conceitos. Os profissionais de design gráfico entendem que a escolha por um processo de impressão, como a serigrafia, baseado em um determinado conceito, poderá trazer um grande diferencial a um trabalho impresso, e para o próprio cliente/marca em última instância. Porém, essa escolha está na contramão do mundo atual, onde aquilo que é mais rápido é compreendido como a melhor escolha, e acaba-se por optar pelo menor prazo, e economia de tempo, em detrimento da qualidade e do diferencial agregado.

Vale ressaltar que a escolha final pelo tipo de impressão a ser empregado não é uma responsabilidade do designer gráfico, mas de seu cliente; é, sim, responsabilidade do designer gráfico indicar qual é o processo de impressão que trará melhor resultado ao projeto, mas de praxe é o cliente quem detém o poder da palavra final, a qual geralmente tende a levar em consideração a solução mais rápida e econômica, qual seja: a impressão digital em detrimento da impressão serigráfica.

\section{Valor histórico da serigrafia}

Para que se entenda a fundo como o processo de impressão serigráfico está atrelado a um valor histórico, estético e de tradição, é necessário visitar a história da serigrafia. Vale aqui ressaltar a dificuldade de se encontrar uma obra, brasileira ou não, específica sobre esse assunto. Estão disponíveis as obras Impressos no Brasil, dois séculos de livros brasileiros, dos organizadores Anibal Bragança e Márcia Abreu (2010), e O Gráfico Amador: As origens da moderna tipografia brasileira, de Guilherme Cunha Lima (2014), que oferecem ricos relatos históricos, mas, com ênfase na impressão litográfica ou offset, pois nessas obras vislumbra-se o processo de impressão de livros especificamente. Nelas nada é mencionado sobre a serigrafia, pois esse processo não é comumente aplicado à impressão de livros - sendo uma das razões o resultado final que se obtém com esse tipo de impressão, e o outro motivo está atrelado ao orçamento de impressão, já que para grandes quantidades a impressão em serigrafia apresenta custo muito superior ao ser comparada à impressão offset.

Segundo Biegeleisen (1971), podemos entender que não existe nenhum registro único e consensual sobre quem foi o autor da descoberta do estêncil ou serigrafia, ou seja, alguém que possa ser comparado a Joanes Gutenberg, que desenvolveu a Tipografia no século XV, ou até mesmo a Alois Senefelder, responsável pelo advento da Litografia. O princípio da serigrafia, como é sabido até o momento, baseia-se no desenvolvimento da técnica do estêncil, utilizada durante 
séculos. Ainda de acordo com Biegeleisen (1971), tem-se que o primeiro trabalho experimental utilizando-se a técnica de impressão permeográfica, tendo a tela de estêncil como matriz, ocorreu nos anos 60, e o meio artístico passou a reconhecer e dar valor ao processo, o qual frequentemente era utilizado como complemento para a xilografia e para pinturas feitas com pincel. Ainda para Biegeleisen (1971), na Inglaterra dos anos 70, quando o papel de parede era feito de lã, os estênciles eram utilizados para aplicar um acabamento a tais revestimentos. E na França do começo dos anos 80 , John Papillon, o pai do papel de parede, prosperou com sua empresa, criando e imprimindo seus produtos utilizando o método do estêncil.

Pode-se dar o crédito de precursores do desenvolvimento da permanência infinita da técnica do estêncil para os japoneses. Eles aprimoraram a técnica, ligando as partes soltas e vulneráveis do estêncil através de fios de seda ou cabelos humanos, montando uma rede que se assemelha à teia de aranha, forte o suficiente e ao mesmo tempo delicada.

Esse foi o primeiro passo para o desenvolvimento do processo permeográfico e para sua perenidade como processo de impressão. Entende-se como processo permeográfico o processo que define a maneira como se prepara a matriz utilizada na serigrafia. Segundo Villas Boas (2008), permeografia é a impressão realizada com uma matriz permeável, ou seja: os elementos que serão impressos são formados por áreas permeáveis ou perfuradas na matriz. Dessa maneira, a tinta passa pelas áreas permeáveis e imprime sobre o substrato desejado, que no caso da serigrafia contempla vários tipos de superfície, tais como papel, madeira, metal, tecido, alvenaria, plástico, vidro e etc.

Não faz muito tempo, os trabalhos impressos a partir de telas de estêncil (ou serigrafia) não eram reconhecidos como trabalhos impressos, pois eram feitos através de uma técnica considerada manual, e ao mesmo tempo não eram considerados trabalhos de arte, pois eram reconhecidos como tendo "múltiplos originais".

A técnica desenvolvida pelos japoneses a partir da trama, dos fios e da tela como suporte, estava só preparando terreno para a maneira como é conhecida hoje o que se designa como matriz de impressão em serigrafia. Atualmente, pode-se dividir essa técnica em três principais aplicações: gráfica, artística e industrial, cada uma possuindo suas características próprias.

Apesar da impressão em serigrafia ter um início incerto, foi nos EUA que esse processo teve um grande impulso como ofício comercial. Na época da Primeira Guerra Mundial teve início um grande interesse por esse processo de impressão, pois foi um período da história ocidental em que houve o surgimento de cadeias de lojas e sindicatos, aumentando a necessidade de cartazes de propaganda. Esses cartazes eram produzidos em grandes quantidades para que fossem pintados à mão, mas não em quantidades suficientes para que fossem impressos com litografia ou tipografia.

Empreendedores perceberam o mercado rentável da serigrafia, reconhecendo este método como bastante barato para a duplicação, utilizando um equipamento simples e fácil de se construir, além de ser também um processo altamente versátil, podendo gerar a impressão sobre quaisquer superfícies, das mais diversas naturezas, em qualquer formato, gramatura, e qualquer tonalidade de cor de tinta. Sendo, portanto, um dos poucos processos com que se pode imprimir utilizando a tinta na cor branca. 


\section{Serigrafia e estética}

Conforme Adorno (2002), a técnica da indústria chegou à estandardização e à produção em série, sacrificando aquilo pelo qual a obra se distingue. Seguindo esse mesmo pensamento, quando o designer gráfico chega à etapa da indicação do processo de impressão, ele poderá seguir o caminho da estandardização, que em tempos atuais corresponderia à opção pela impressão digital, sacrificando o trabalho final, deixando de ter um diferencial - o qual poderia alcançar com a escolha pela serigrafia.

Quando se faz a opção pela impressão em serigrafia está-se em busca de um diferencial de qualidade, pois este tipo de impressão traz um resultado estético diferenciado ao trabalho final. Como exemplo, a tinta impressa em serigrafia ficará com um leve volume, ou relêvo, e também é possível modificar o resultado final utilizando-se uma mesma cor de tinta variando-se apenas o efeito: fosco ou brilho. A serigrafia também possibilita a impressão de soluções inusitadas como cores escuras sobre fundos escuros, e também permite a impressão de uma cor da mesma cor do suporte sobre a qual se deposita, e ainda, realizar a impressão da tinta branca sobre o papel também branco. A distinção da superfície impressa, nestes casos, se daria pela diferença de brilho e relêvo - ou seja, pelas qualidades estéticas.

Entende-se melhor o valor estético da impressão em serigrafia observando os exemplos abaixo de peças gráficas do acervo da Zen Serigrafia. A Figura 01 é referente a um cardápio, o qual foi impresso com tinta branca sobre o papel cartão de cor escura. A Figura 02 é relativa a um flyer (lâmina) de uma pousada, que foi impresso sobre PVC (plástico) azul. A Figura 03 refere-se a um convite de lançamento, para o qual o envelope foi impresso no acetato (plástico) transparente, e já a Figura 04 mostra um cartão de visita, impresso em duas cores de tinta: branca e laranja sobre a superfície do papel escuro. 
Figura 1 - Tinta branca sobre cartão Kraft

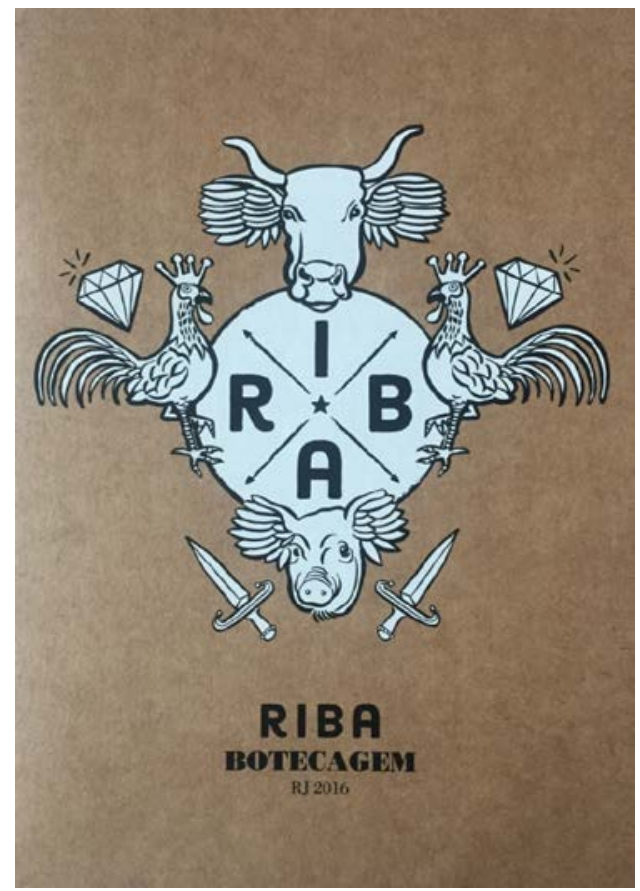

Fonte: acervo da Zen Serigrafia.

Figura 2 - Duas cores sobre PVC

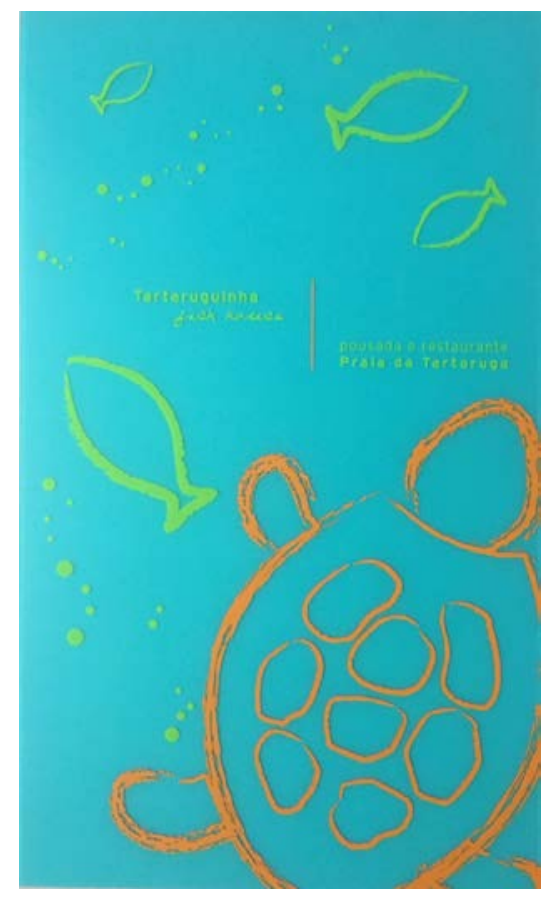

Fonte: acervo da Zen Serigrafia. 
Figura 3 - Envelope: preto sobre acetato transparente

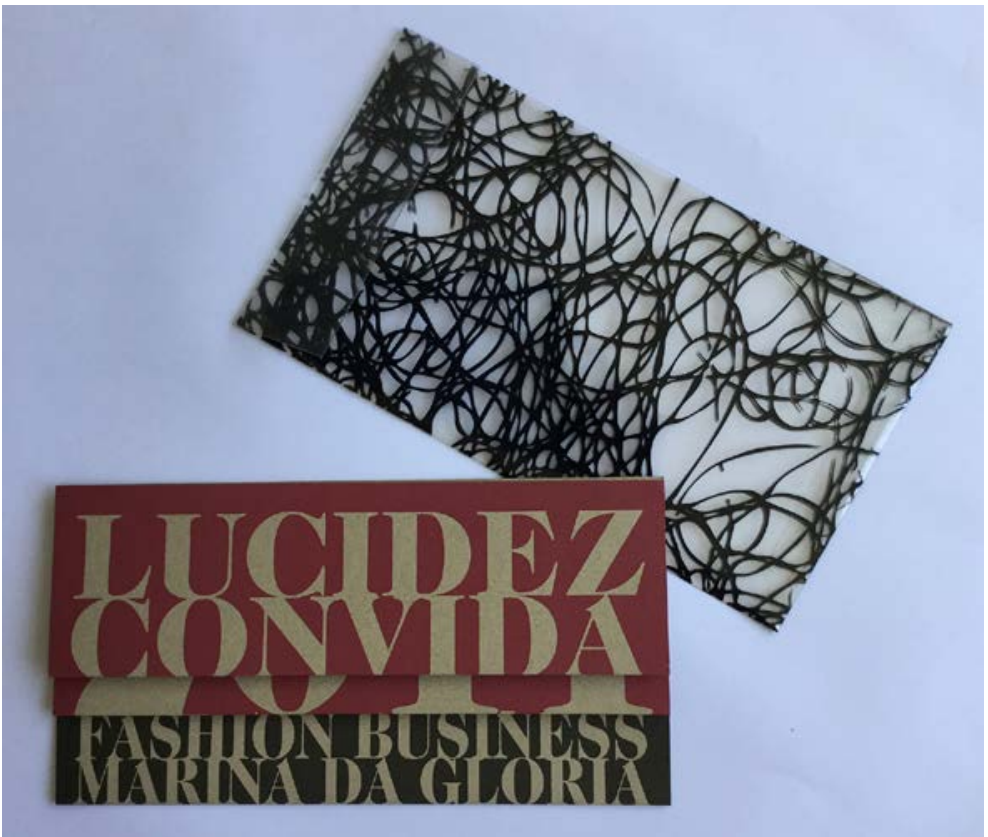

Fonte: acervo da Zen Serigrafia.

Figura 4 - Duas cores sobre cartão escuro

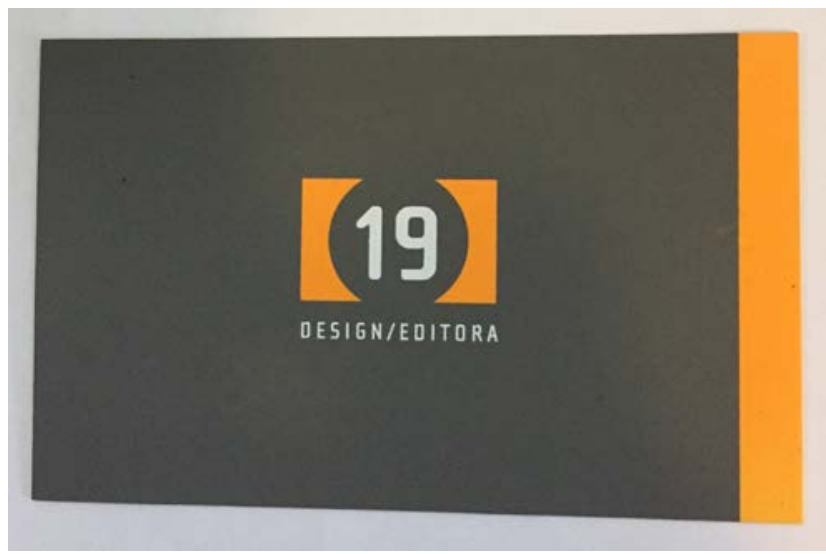

Fonte: acervo da Zen Serigrafia.

Vale lembrar que essa peça cartão de visita virá a ser utilizada como exemplo mais adiante, neste artigo, a fim de demonstrar a comparação com a impressão digital. Essas possibilidades de impressão apresentadas anteriormente são apenas alguns exemplos das características únicas desse tipo de impressão, como o uso da tinta branca, impressão em PVC, transparente ou não.

Lipovetsky e Serroy (2015) apresentam as quatros eras da estetização do mundo. A primeira é denominada como a artealização ritual. A segunda como a estetização aristocrática. A terceira como a moderna estetização do mundo e a quarta como a era transestética.

Entende-se que a impressão em serigrafia se enquadra na terceira era, a moderna 
estetização do mundo, pois, segundo Lipovestsky, o universo industrial e comercial foi o principal artífice dessa época. Segundo Biegeleisen (1971), a impressão em serigrafia se desenvolveu como ofício comercial após a Primeira Guerra Mundial, pois nessa época teve início um grande interesse por esse processo de impressão, sendo um período da história ocidental que testemunhou o surgimento de cadeias de lojas e sindicatos, aumentando a necessidade por comunicação em cartazes de propaganda. A impressão digital se enquadra na era transestética, pois segundo Lipovetsky (2004), nessa época as pessoas estão obcecadas pelo descartável, pelo excesso, pelo rápido e fácil, e a impressão digital se desenvolveu para atender com maior facilidade, quantidade e rapidez à uma demanda cada vez mais premente. A impressão digital propicia inclusive o descarte com maior facilidade, afinal se o material impresso apresentar alguma imperfeição, rapidamente poderá ser reimpresso, e a baixo custo.

\section{Orçamentos comparativos}

A fim de melhor explicitar o propósito deste artigo, deve-se observar a comparação dos orçamentos, feitos em setembro de 2017, com dois fornecedores distintos: a gráfica Power Image especializada em impressão digital, e com a gráfica Zen Serigrafia - especializada em impressão serigráfica. As empresas foram escolhidas por serem ambas referências em suas especialidades.

Ambos os orçamentos apresentam as seguintes especificações gráficas: impressão de cartão de visita - formato: 9,0 × 5,0 cm; cores: 2/0; papel: cartão supremo 300 grs.; tiragem: 500 unidades; acabamento: corte reto. O orçamento apresentado pela gráfica Zen Serigrafia ficou no valor total de $\mathrm{R} \$ 698,50$, com a entrega no prazo de uma semana. O orçamento do fornecedor digital Power Image ficou no valor total de $\mathrm{R} \$ 265,00$, com entrega no prazo de um dia útil.

De acordo com os dados apresentados acima, entende-se que quando o designer gráfico sugere a seu cliente a impressão em serigrafia, ele não possui como parâmetro o menor custo ou o prazo mais rápido. Este profissional está à procura dos atributos estéticos da serigrafia, trazendo um resultado final diferenciado ao trabalho.

O processo de impressão em serigrafia já foi muito popular mas vem perdendo muito espaço tendo em vista o contraste de custos contra o processo digital. Aponta-se então para questionamentos como: terão os valores se invertido ou se deturpado a ponto de considerar-se a qualidade um ideal inferior à quantidade? Segundo Lipovetsky (2004), o que mudou foi principalmente o ambiente social e a relação com o presente. O período pós-moderno é marcado pela "primazia do aqui - agora". Seguindo esta lógica é inadmissível se esperar uma semana por uma impressão que poderá ser entregue em apenas um dia. Mudou muito a relação do ser humano com o tempo, e da produção com o tempo. Na Figura 5 observa-se uma oferta de produção de cartões por impressão digital. São oferecidos 1000 unidades por $\mathrm{R} \$ 14,99$. Ora, este valor irrisório poderá ter como efeito nocivo não só a concorrência desleal a processos tradicionais e semiartesanais como a tipografia e a serigrafia, mas também denigre o valor do produto pois passa a gerar uma percepção de matéria descartável, efêmera. Essa percepção também poderá resvalar para o profissional de design gráfico, afinal como cobrar por um projeto gráfico quando o custo de produção é tão insignificante? Este raciocínio poderá ser aplicado a diversas outras peças gráficas, mais complexas do que o simples cartão de visitas. 
Figura 5 - Promoção da impressão digital
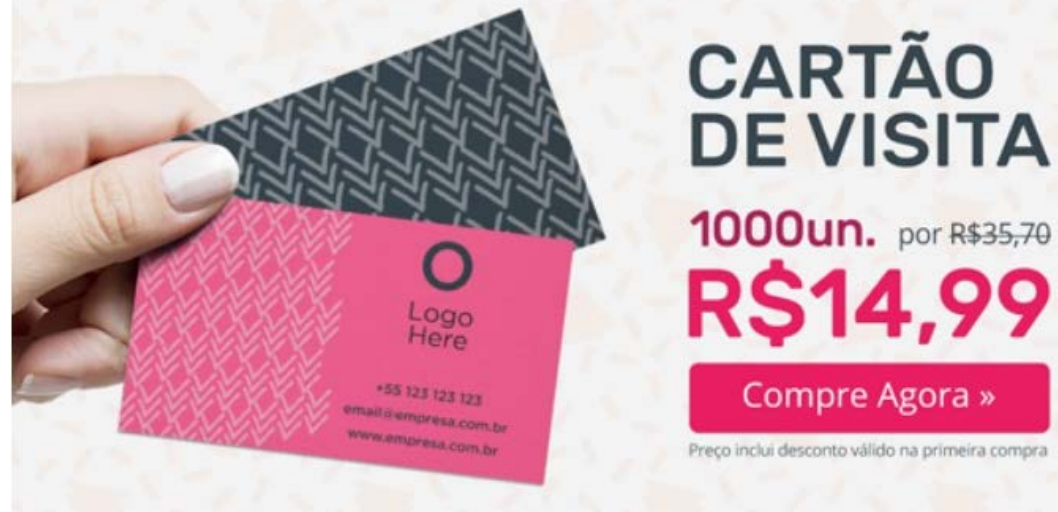

1000un. por $R \$ 35,70$

R\$\$14,99

Compre Agora »

Fonte: https://www.360imprimir.com.br/ (acesso em 24/03/2018)

É o que conduz à compreensão de que quando o designer gráfico consegue convencer seu cliente pela escolha do processo de impressão em serigrafia, atualmente, ele está conseguindo transgredir um senso comum no sentido da economia do tempo, a qual já é um valor intrínseco às sociedades pós-modernas. É como se o designer gráfico tivesse, com essa conquista, conseguido parar o tempo.

\section{A banalização dos valores estéticos}

Segundo Vargas Llosa (2013), vivemos em um mundo da quantidade em detrimento da qualidade, com o desaparecimento dos consensos mínimos sobre os valores estéticos. Dessa maneira, quando se faz a escolha pela impressão digital, está-se em busca da quantidade, rapidez e baixo custo, e não há valor intrínseco à qualidade final. Deixa-se de lado valores estéticos diferenciados. Ao se fazer a escolha pela impressão em serigrafia, resgata-se a busca da qualidade e de valores estéticos diferenciados, como se numa volta ao passado.

Vale ressaltar a lembrança do que já foi exposto anteriormente, que a definição sobre o processo de impressão que será utilizado, em um determinado trabalho, caberá sobretudo ao cliente, enquanto que ao profissional de design cabe aconselhá-lo, e indicar o processo visando o melhor resultado possível.

A gráfica Zen Serigrafia, no Rio de Janeiro, dá continuidade a uma tradição através da permanência de um processo de impressão gráfico, mantendo um valor histórico, pois essa gráfica perpetua, agora por trinta anos, o tipo de processo de impressão permeográfico, enquanto muitas das gráficas que se iniciaram nesse setor sucumbiram a uma tecnologia atual, passando de uma gráfica de serigrafia para uma gráfica digital.

Segundo Reis (2007), e sua definição sobre Tipologias de Valor, entende-se que a Zen Serigrafia se enquadra no "valor histórico", pois, segundo a autora, com o passar do tempo os objetos, e as técnicas, passam a assumir um valor histórico. Portanto, ao optar pela gráfica digital, leva-se à banalização da impressão, deixa-se de lado não somente qualidades estéticas, mas valores como a tradição: justamente o que a serigrafia é capaz de proporcionar a um trabalho de impressão, 
seja a um cartão de visita, cartaz ou convite.

\section{Conclusão}

Desde a implementação da tecnologia digital no setor da impressão, a serigrafia vem perdendo espaço no mercado gráfico, cada vez mais se apequenando. Baseando-se na lógica perversa da economia de tempo e recursos, a nova tecnologia atropela outros processos anteriores a ela da mesma forma que o processo de evolução se dá na natureza e algumas espécies substituem outras, às vezes de forma abrupta. No entanto, alguns expoentes recusam-se a tombar diante deste processo orgânico da evolução. A Zen Serigrafia, empresa do setor gráfico do Rio de Janeiro, vem a ser uma destas resistências devido à qualidade do trabalho que entrega há trinta anos - reconhecido como de excelência pela comunidade de Designers gráficos da cidade. Possui um valor intrínseco à tradição que enverga. Diante do exposto, o designer gráfico, profissional que atua de modo a conciliar os interesses de seu cliente com a qualidade do fornecedor - neste caso a empresa gráfica - possui uma percepção bastante diferenciada quanto a este cenário do setor gráfico. No seu modo de ver, o processo de impressão deve ser escolhido sempre em função de suas qualidades intrínsecas e únicas - e não somente de acordo com a lógica econômica, de forma que o produto final possua um maior valor agregado, o qual estaria ligado a questões de cunho estético. A estética abrange aquilo que é da natureza do sensível: daquilo que se percebe com o conjunto de sentidos e que vão além do ver. No caso da impressão serigráfica, ela estimula também o sentido do tato, além de permitir toda uma gama de possibilidades de combinações de cores com materiais, inatingível com os processos digitais. Daí tem-se que, embora a impressão digital tenha alcançado cada esquina dos centros urbanos e também as residências, não poderá substituir, em termos de qualidade, um processo tão primoroso quanto a serigrafia. Se por um lado Serroy e Lipovetsky (2015) expõem a estetização do mundo, no qual todos os serviços e produtos possuem uma aparência cuidadosamente planejada e estetizada, Vargas Llosa (2008) aponta para a banalização dos valores estéticos com a prevalência da quantidade em detrimento da qualidade. Neste cenário, para o designer gráfico fica o sentimento de que possui um papel relevante no sentido de contribuir para a permanência dos valores estéticos deste serviço - que cada vez mais ocupará um nicho - ao longo do tempo.

\section{Referências}

ADORNO, T. W. Indústria cultural e sociedade. São Paulo: Paz e Terra, 2002.

BIEGELEISEN, J. I. Screen printing a contemporary guide to the technique of screen printing for artists, designers, and craftsmen. New York: Watson-Guptill Publications, 1971.

BRAGANÇA, A.; ABREU, M.(organizadores). Impressos no Brasil, dois séculos de livros brasileiros. São Paulo: Editora Unesp, 2010.

GORDON, B.; GORDON, M. O essencial do design gráfico. 2 ed. rev. São Paulo: Editora SENAC São Paulo, 2014.

LIMA, G. C. 0 gráfico Amador: As origens da moderna tipografia brasileira. 2 ed. Rio de Janeiro: Verso Brasil Editora, 2014. 
LIPOVETSKY, G. Os tempos hipermodernos. São Paulo: Editora Barcarolla, 2004.

LIPOVETSKY, G.; SERROY, J. A estetização do mundo: Viver na era do capitalismo artista. 1. ed. São Paulo: Companhia das Letras, 2015.

REIS, Ana Carla Fonseca. Economia da cultura e desenvolvimento sustentável: o caleidoscópio da cultura. Baureri, SP: Manole, 2007.

VARGAS LLOSA, Mario. A civilização do espetáculo: uma radiografia do nosso tempo e da nossa cultura. 1. ed. Rio de Janeiro: Objetiva, 2013.

VILLAS-BOAS, André. Produção gráfica para designers. 3. ed. Rio de Janeiro: 2AB, 2008. 